\title{
Mechanism of late failure of the Alvarez disc valve prosthesis
}

\author{
JOHN L GIBBS, \\ DAVID A WATSON, * LEON M GERLIS*
}

From the ${ }^{\star}$ Cardiac Research Unit and †Non Invasive Heart Unit, Killingbeck Hospital, Leeds

\begin{abstract}
SUMMARY An Alvarez disc valve prosthesis had been implanted in the mitral and tricuspid positions in 15 patients between 1964 and 1967 in this hospital. Of these 15 patients, only three survived longer than 10 years, all three dying unexpectedly between 16 and 18 years postoperatively. Two deaths were a direct result of disruption of the Alvarez prosthesis. The third patient was not examined at necropsy, but in retrospect the history was highly suggestive of valve malfunction. Cross sectional and pulsed Doppler echocardiography made valuable contributions to the diagnosis in both cases of valve disruption and, when available, should be part of the primary investigation of suspected prosthetic heart valve failure.

The Alvarez valve prosthesis is liable to erosive wear which may cause late detachment of the disc from the valve ring with abrupt and catastrophic haemodynamic consequences.
\end{abstract}

The Alvarez disc valve prosthesis, made of polypropylene, was developed at the Experimental Surgical Unit at the Postgraduate Medical School, London, in the early 1960s. ${ }^{1}$ It was first introduced into clinical use in 1964. Fifteen of these prostheses were implanted at Killingbeck Hospital between 1964 and 1967,2 seven in the mitral position and eight in the tricuspid position. One valve in the tricuspid position was replaced by a different prosthesis after the development of paraprosthetic leak, and two patients died perioperatively. Of the 12 remaining patients, nine died within five years of operation (without evidence of valve failure) and three survived longer than 10 years. One of these three patients died after a 48 hour pyrexial illness in 1983 and the other two died in 1984 as a direct result of mechanical failure of the Alvarez prosthesis. In these two patients the valve disc had become detached from the valve ring owing to erosion of the polypropylene disc struts.

Use of the Alvarez prosthesis was abandoned at this hospital in 1967 because of the high incidence (62.1\%) of thromboembolic complications reported when the prosthesis was used in the mitral position. ${ }^{3}$

Requests for reprints to Dr J L Gibbs, The Non Invasive Heart Unit, Killingbeck Hospital, York Road, Leeds LS14 6UQ.

Accepted for publication 21 January 1985

\section{Patients and methods}

\section{CASE REPORTS}

Case 1

A 61 year old man was admitted for investigation of jaundice and hepatomegaly. Eighteen years previously he had undergone aortic, mitral, and tricuspid valve replacements for rheumatic valve disease with a No 10 Starr-Edwards, a No 3 Starr-Edwards, and a $2.25 \mathrm{~cm}$ Alvarez prosthesis respectively. Initial investigation suggested cholelithiasis. During induction of anaesthesia before cholecystectomy he suffered a cardiac arrest, from which he made a good recovery, but after this he found his exercise tolerance had deteriorated. He was readmitted at a later date, and endoscopic retrograde cannulation of the pancreatic duct and a sphincterotomy were performed under antibiotic cover. After this procedure he became pyrexial and increasingly icteric, with signs of worsening right heart failure and a low cardiac output. The chest radiograph showed gross cardiomegaly and the electrocardiogram widespread repolarisation changes. Echocardiography showed moderately impaired left ventricular function, with a dilated and poorly contracting right ventricle. The aortic and mitral StarrEdwards prosthetic valves appeared normal, but the tricuspid valve disc was not visible. Pulsed Doppler echocardiography showed very high blood velocities 
across the tricuspid valve (Fig. la) and no prosthetic valve clicks were detected, strongly suggesting valve malfunction. Despite intensive supportive therapy, the patient died two days later.

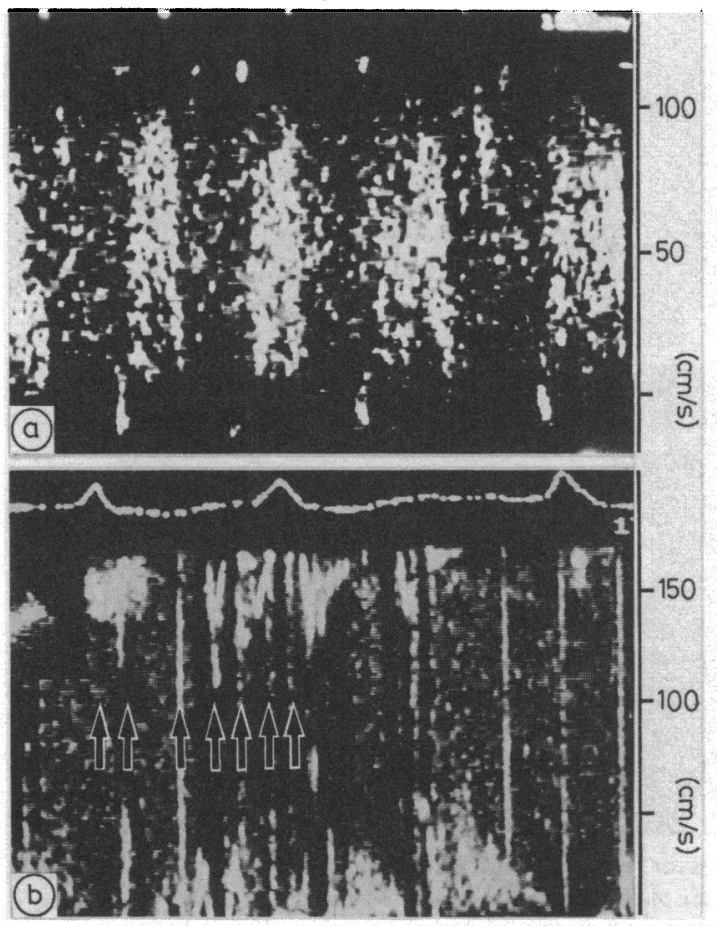

Fig. 1 Pulsed Doppler echocardiograms of (a) right ventricular inflow in case 1 showing abnormally increased peak velocity with aliasing above $100 \mathrm{~cm} / \mathrm{s}$, approximately twice the normal value; and (b) left ventricular inflow in case 2 showing a birarre pattern with multiple abnormal velocity waves (arrowed) due to the chaotic motion of the valve disc within the left ventricle.

At necropsy the heart was found to be considerably enlarged. When the right lung was removed the disc of the Alvarez tricuspid valve was found to lie in the right pulmonary artery. The valve ring had remained in the tricuspid position. The mitral and aortic prostheses appeared to be normal. Closer examination of the Alvarez prosthesis showed considerable areas of wear (Fig. 2), particularly of the disc struts, which had been worn down to a shark's tooth appearance and were considerably diminished in size, allowing the disc to displace freely from its ring. The ring itself was also worn in the area of contact with the strut. There were multiple pigment stones in the gall bladder, and the liver showed severe cardiac cirrhosis.

\section{Case 2}

A 56 year old woman suffered a cardiac arrest on the way to hospital, having become acutely and severely dyspnoeic. A prolonged resuscitation procedure resulted in restoration of cardiac output followed by status epilepticus. Sixteen years earlier she had undergone mitral valve replacement with a $2.25 \mathrm{~cm}$ Alvarez prosthesis for rheumatic valve disease.

Examination of the cardiovascular system showed pronounced hypotension, a hyperdynamic left ventricular impulse, loud prosthetic valve clicks, and a soft systolic murmur audible at the left sternal edge. The chest radiograph showed gross cardiomegaly with pulmonary oedema and the electrocardiogram a bizarre cardiac rhythm. Echocardiography showed a well contracting, hypertrophied left ventricle which contained a freely moving echo dense object (Fig. 3). This appeared to merge with the mitral valve ring in systole and to move rapidly to the apex of the ventricle in diastole. Doppler echocardiography produced high pitched squeaking sounds in place of the usual prosthetic valve clicks and showed a bizarre flow velocity pattern in the left ventricular inflow tract (Fig. 1b). A diagnosis of mechanical prosthetic valve failure was made, but the patient failed to show any sign of cerebral recovery. Her condition rapidly deteriorated and she died 24 hours later.

At necropsy the valve disc was found to be lying in the valve ring but with the struts in an abnormal position. When the heart was lifted up the disc fell freely into the left ventricular cavity, returning to its previous position when the heart was inverted. As in the patient in case 1 the prosthesis showed signs of advanced erosion of the disc struts, which again were sharpened and greatly reduced in size, allowing the disc to move freely in and out of the valve ring. The disc also showed considerable wear at its point of diastolic contact with the ring, which could well have produced prosthetic leakage. The valve ring itself was worn in a similar fashion to that in the first patient (case 1) in the area of contact with the disc struts (Fig. 4).

\section{Case 3}

A 44 year old man, who had undergone mitral (StarrEdwards) and tricuspid (Alvarez) valve replacement in 1967, was admitted to his local hospital having become suddenly unwell with diarrhoea, pyrexia, and confusion. He was found to have a severely raised jugular venous pressure and Gram positive bacteraemia. Despite an initial apparent improvement after antibiotic treatment, he developed disseminated intravascular coagulopathy and suffered a cardiac arrest from which he did not recover. Unfortunately, a necropsy was not performed. The short history preceding death had similarities with that in the patient in case 1 , and retrospective review of the case records showed that the pronounced increase in jugular venous pressure had not been present at a recent out- 

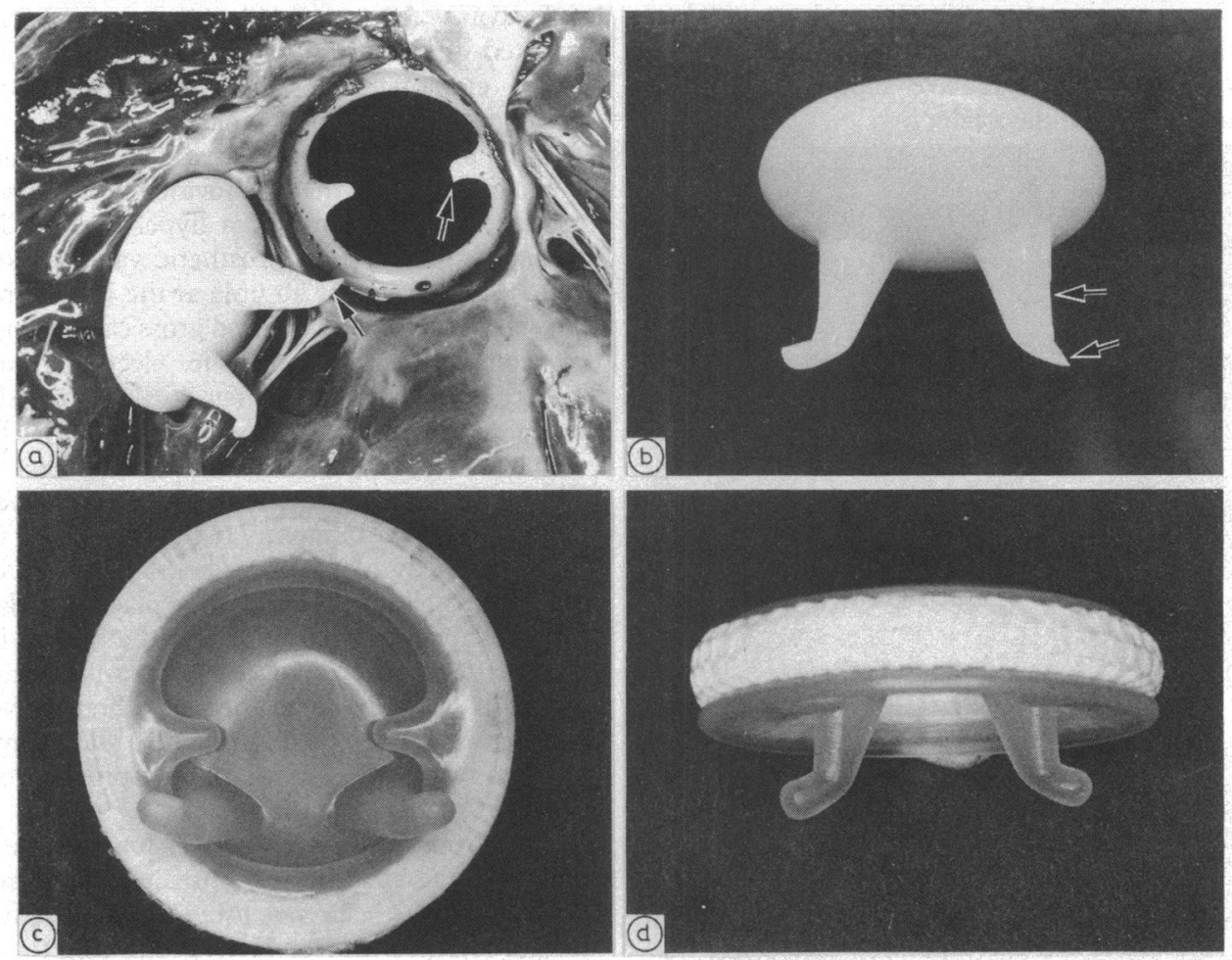

Fig. 2 (a) The valve disc and ring in case 1 showing the areas of wear (arrowed), which allowed the disc to displace. The ring is worn at the site of contact with the retaining struts of the disc, which are themselves badly eroded. (b) The areas of disc wear are seen more clearly in profile. The extent of wear is emphasised by comparison with an unused Alvarez prosthesis $((c)$ and $(d))$.

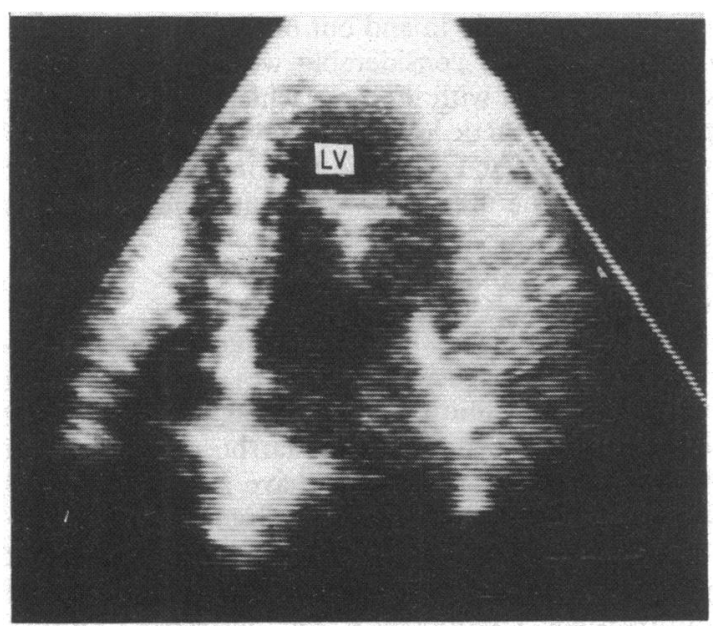

Fig. 3 Cross sectional echocardiogram in the apical fourchamber view in case 2 showing the echo dense valve disc lying within the left ventricular cavity (LV).

patient assessment. Without postmortem information there can be no proof of prosthetic valve disruption causing this patient's unexpected death, but there is a strong possibility that this was the case.

\section{Discussion}

Diagnosis of prosthetic valve mechanical failure may be difficult. Muffled or absent prosthetic clicks may be a valuable indicator of valve malfunction, ${ }^{4-6}$ and particular emphasis has been placed on the importance of the opening sound of the Starr-Edwards prosthesis in the aortic position. ${ }^{7}$ Phonocardiography may be useful in detecting more subtle changes in prosthetic sounds. ${ }^{8}$ Echocardiographic assessment of prosthetic ball ${ }^{9}$ or disc ${ }^{10}$ motion may provide useful information, particularly in valve obstruction, and assessment of left ventricular function can help to exclude poor myocardial contraction as a cause of diminished click volume. " Nevertheless, even when these techniques together with fluoroscopic screening of the valve are used, discernible abnormalities may occur only when damage to the prosthesis is well advanced. ${ }^{712}$

Our second patient (case 2) is the first reported in whom the valve clicks were increased rather than 


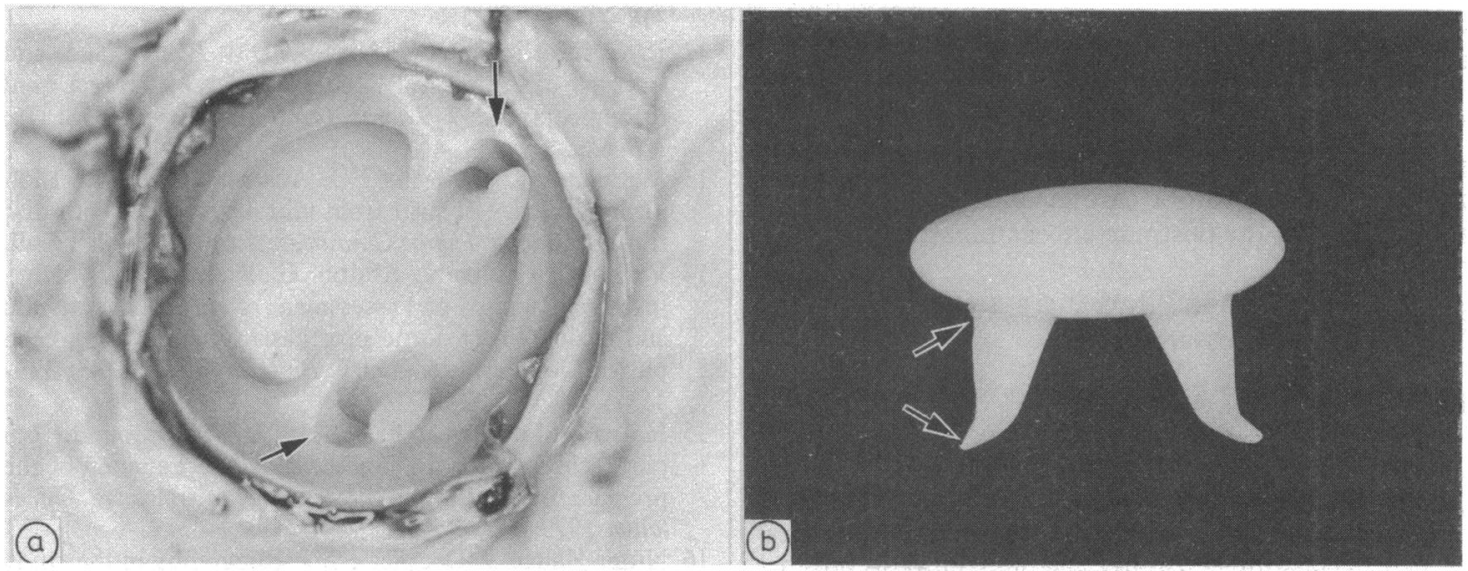

Fig. 4 Morphological appearance of the prosthetic valve removed from case 2. (a) The disc has been replaced in its correct position in the valve ring. The ring itself has worn (arrows) considerably more than that in case 1 . (b) shows the extent of strut erosion (arrows).

diminished despite complete separation of the disc from the valve ring. This was undoubtedly due to the continued movement of the disc within the left ventricular cavity. The disc struts, which are an integral part of the disc, probably prevented it from being ejected from the heart. Valve clicks were, however, absent in two reported cases in which the Björk-Shiley discs remained within the left ventricle ${ }^{5}$ and the left atrium ${ }^{13}$ after valve disruption, despite the discs lying free within the heart cavities at the time of emergency reoperation.

In two of our patients (cases 1 and 2) cross sectional and pulsed Doppler echocardiography made important contributions to the diagnosis. Doppler may provide useful information on prosthetic valve obstruction and paraprosthetic leak in aortic, ${ }^{14}$ mitral, ${ }^{15} 16$ and tricuspid ${ }^{17}$ positions; our first two cases indicate that it may also be-invaluable in the diagnosis of valve disruption. We now regard both these investigations as an essential part of evaluation of prosthetic valve malfunction.

There can be no doubt that immediate valve replacement is the only effective treatment for valve disruption. 4-71112 Neither of our first two patients underwent repeat surgery as one (case 1) was septicaemic and in hepatic and renal failure and the diagnosis was uncertain; the other (case 2) failed to show evidence of recovery of cerebral function after her prolonged resuscitation procedure.

The most common cause of embolisation of prosthetic valve discs is fracture of either the disc struts or the disc itself. Both major strut ${ }^{413}$ and minor strut $^{5618}$ fracture of the Björk-Shiley prosthesis with resulting disc embolisation have been reported, but there was little evidence of disc wear in these cases. Even the current pyrolitic carbon discs may frac- ture, ${ }^{19}$ and signs of very early disc burnishing have been reported in valves even after a few hours in patients who died on the operating table. ${ }^{20}$ Nevertheless, the clinical performance of the Björk-Shiley valve has been excellent overall, and Clark et al found only minimal signs of valve wear after 973 million cycles of accelerated fatigue testing. ${ }^{21}$ Titanium valve struts may also be liable to wear in the DeBakey ball valve. ${ }^{22}$ In contrast, Alvarez valve disruption in two of our patients (cases 1 and 2) occurred after approximately 600 million cycles, by which time very advanced wear was apparent.

Plastics might logically be expected to undergo more wear than harder materials such as pyrolite, and published reports support this. Severe wear of the Teflon disc of a Wada-Cutter valve may also occur with remarkably similar findings to those in our cases. ${ }^{23}$ The Beall valve Teflon disc has also been shown to undergo excessive wear in both its early and later strengthened forms. ${ }^{24} 25$

\section{CONCLUSIONS}

The Alvarez disc valve is subject to severe wear, which may lead to valve disruption after approximately five to six hundred million cardiac cycles. We strongly recommend that any patient with an Alvarez prosthesis be offered valve replacement.

Plastics such as polypropylene and Teflon show signs of wear much earlier than pyrolite and titanium and are therefore unsuitable materials for the construction of prosthetic valve discs in their present forms. Prolonged in vitro accelerated fatigue testing may be necessary before serious wear is detected.

The early diagnosis of prosthetic valve disruption is essential if the patient is to survive and may be greatly 
assisted by cross sectional and pulsed Doppler echocardiography.

We thank Mr Duncan Walker for permission to report case 2, Dr B Lynch for performing the postmortem examination of case 1 , and Dr S Apparacio for performing the postmortem examination of case 2 .

JLG, GAD, AS, and LMG are supported by the National Heart Research Fund.

\section{References}

1 Melrose DG, Bentall HH, McMillan IKR, et al. Evolution of a mitral valve prosthesis. Lancet 1964; ii: 623-4.

2 Edmunds L H Jr, Wooler GH, Watson DA. Clinical experience with the Alvarez and Starr-Edwards prosthetic mitral valves. I Thorac Cardiovasc Surg 1966; 51: 185-94.

3 Mashhour YAS, Garcia JB, Ionescu M, Wooler GH. Mitral valve replacement with Alvarez prosthesis: long term results. Thorax 1969; 24: 287-90.

4 Larrieu AJ, Puglia E, Allen P. Strut fracture and disc embolization of a Björk-Shiley mitral valve prosthesis: localization of embolized disc by computerized axial tomography. Ann Thorac Surg 1982; 34: 192-5.

5 Ibarra F, Gutierrez A, Martinez F, Carreras L, Lopez C, Alonso-Lej F. Fracture of the outlet strut of a BjörkShiley mitral prosthesis: emergency operation with survival. F Thorac Cardiovasc Surg 1984; 87: 315-8.

6 Sethia B, Quin RO, Bain WH. Disc embolisation after minor strut fracture in a Björk-Shiley mitral valve prosthesis. Thorax 1983; 38: 390-1.

7 Hylen JC. Mechanical malfunction and thrombosis of prosthetic heart valves. Am f Cardiol 1972; 30: 396-404.

8 Harrison EC, Roschke EJ, Matsuno M, Allen JW. Double opening sound related to dysfunction in a caged disc mitral valve prosthesis. Am $\mathcal{F}$ Cardiol 1974; 33: 300-3.

9 Winters WL Jr, Giminez J, Soloff LA. Clinical application of ultrasound in the analysis of prosthetic ball function. Am $\mathcal{f}$ Cardiol 1967; 19: 97-107.

10 Johnson ML, Holmes JH, Paton BC. Echocardiographic determination of mitral disc valve excursion. Circulation 1973; 47: 1274-80.

11 Chandraratna PAN, Lopez JM, Hildner FJ, Samet P, Ben-Zvi J. Diagnosis of Björk-Shiley aortic valve dysfunction by echocardiography. Am Heart $\mathcal{F}$ 1976; 91:
318-24.

12 Joyce LD, Emery RW, Nicoloff DM. Ball variance and fracture of mitral valve prosthesis causing recurrent thromboemboli. I Thorac Cardiovasc Surg 1978; 75: 309-12.

13 McEnany MT, Wheeler EO, Austen WG. Survival following fracture of strut from mitral prosthesis with disc translocation. F Thorac Cardiovasc Surg 1979; 78: 136-9.

14 Veyrat C, Cholot N, Abitbol G, Kalmanson D. Noninvasive diagnosis and assessment of aortic valve disease and evaluation of aortic prosthesis function using echo pulsed Doppler velocimetry. Br Heart F 1980; 43: 393413.

15 Holen J, Simonsen S, Froysaker T. An ultrasound Doppler technique for the noninvasive determination of the pressure gradient in the Biörk-Shiley mitral valve. Circulation 1979; 59: 436-42.

16 Nitter-Hauge S. Doppler echocardiography in the study of patients with mitral disc valve prostheses. $B r$ Heart $\mathcal{f}$ 1984; 51: 61-9.

17 Veyrat C, Ollagnier J, Fremont D, et al. Jugular pulse and flow velocity anomalies: a diagnostic clue to an obstructive tricuspid prosthetic dysfunction. Eur $\mathcal{F}$ Cardiol 1980; 12: 195-205.

18 Sacks SH, Northeast ADR, Watkins J. Late strut fracture in a Björk-Shiley valve prosthesis (current series). $\mathrm{Br}$ Heart $\mathcal{f}$ 1984; 51: 578-80.

19 Norenberg DD, Evans RW, Gundersen AE, Abellera RM. Fracture and embolization of a Björk-Shiley disc: fatal failure of a prosthetic mitral valve. $\mathcal{F}$ Thorac Cardiovasc Surg 1977; 74: 925-7.

20 Silver MD. Wear in Björk-Shiley heart valve prostheses recovered at necropsy or operation. $\mathcal{F}$ Thorac Cardiovasc Surg 1980; 79: 693-9.

21 Clark RE, Swanson WM, Kardos JL, Hagen RW, Beauchamp RA. Durability of prosthetic heart valves. Ann Thorac Surg 1978; 26: 323-35.

22 Paton BC, Pine MB. Aortic valve replacement with the De Bakey valve. I Thorac Cardiovasc Surg 1976; 72: 652-6.

23 Cooper DKC, Sturridge MF. Acute massive mitral regurgitation from prosthetic valve dysfunction. $\mathrm{BrHeart} f$ 1976; 38: 701-5.

24 Jost RG, McKnight RC, Roper CL. Failure of Beall mitral valve prosthesis. F Thorac Cardiovasc Surg 1975; 70: 163-5.

25 Hildner FJ, Robinson MJ. Complications of Beall valve prosthesis [Letter]. Am $\mathcal{F}$ Cardiol 1972; 30: 922. 